\title{
A CASE OF RHINOSPORIDIUM KINEALYI
}

BY

\author{
Major J. N. Duggan, D.O.(Oxon), F.C.P.S. \\ SUPERINTENDENT, SIR C. J. OPHTHALMIC HOSPITAL, AND PROFESSOR OF \\ OPHTHALMOLOGY, GRANT MEDICAL COLLEGE, BOMBAY
}

DURING the last twenty years a few cases of ocular type of rhinosporidium Kinealyi have been published from time to time, and this one is reported below with a view to add one more to those already put on record. The growth, seemed to arise from the semilunar fold of the right eye and involved the adjacent bulbar conjunctiva.

Historical. Rhinosporidium was first discovered in a nasal polypus by Gullermo Seeber at Buenos Ayres in 1896. The growth in this case weighed 20 grammes and was papillomatous in structure and rich in granulation tissue. It was rediscovered by Major O'Kinealy in 1903 and named after him. Kirkpatrick reported a conjunctival form in 1909.(1) Elliot and Ingram in 1912 published a case in which the growth arose from the base of the orbit and also from the skin in the vicinity of the lower lid.(2) Kirkpatrick again reported a case of rhinosporidium of the sac. ${ }^{(3)}$ Tirumurti in $1915^{(4)}$ and Wright in $1922^{(5)}$ reported having found sporozoa in the conjunctiva.

On December 28, 1925 a Mohammedan aged 52 years, presented himself at the out-patient department of the Sir. C. J. Eye Hospital, Bombay, with a growth arising from the vicinity of the inner canthus. On enquiry it was found that a small red papule made its appearance six months previously in the region of the semilunar fold of the right eye. As it rapidly increased in size, the patient sought advice for its treatment.

On examination of the right eye, a papilloma-like growth whose free end was covered by a rounded and thickened scab, was seen protruding through the palpebral fissure at its inner end and preventing complete closure of the lids. It was seen to arise from the semilunar fold and bulbar conjunctiva adjacent to it with a broad base whose inner limit extended horizontally from the inner canthus, which was free from the growth, to a position on the sclerotic 4 to $5 \mathrm{~mm}$. short of the limbus. Vertically it extended about $0.5 \mathrm{~mm}$. above the horizontal line and below as far as the lower fornix. It was of dark red colour and fairly vascular. Patient did not complain of any pain in the eye but felt some when the growth was touched. 'There was slight lacrymation, but the naso-lacrymal apparatus was found normal. Vision, reaction of pupil, fundus, movements and tension of the right eye were normal. There was no enlargement of lymphatic glands in the neck. As 


\section{CASE OF Rhinosporidium Kinealyi}

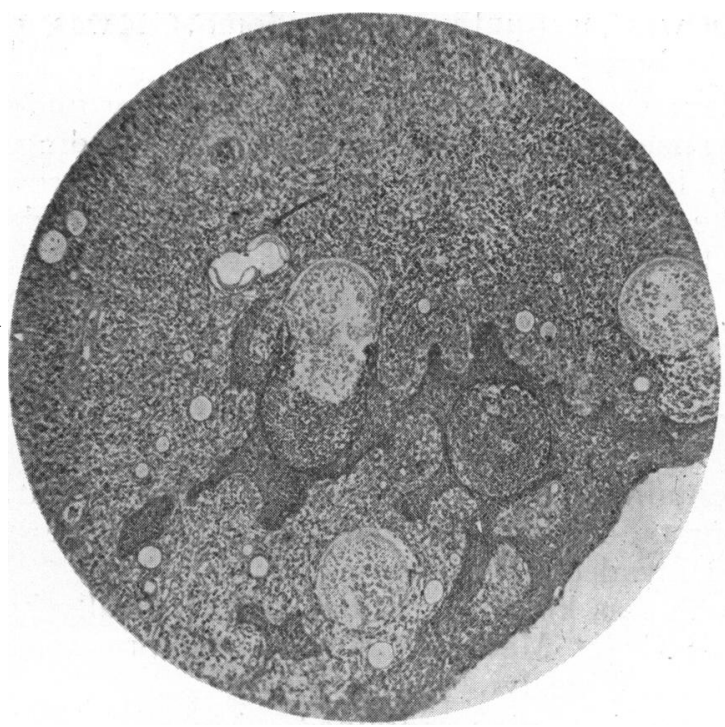

No. $1 .-3$ in. $\times 3$ Leitz.

Proliferation of stratified epithelium and cysts in subepithelial tissue.

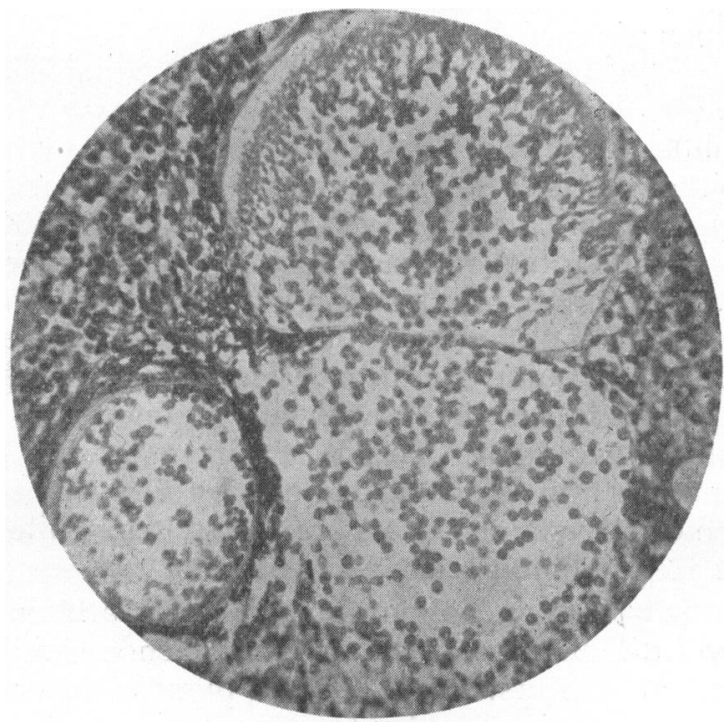

No. 2. $-\frac{1}{6}$ in. $\times 3$ Leitz $\times 400$.

The small cyst is seen with its intact wall and spores. The larger one, which is fully matured, shows proliferation of epithelium lining it and invasion of leucocytes for absorption; and third one above the second is seen in a burst condition. 
the growth was not unlike a papilloma, it was provisionally diagnosed as horny papilloma.

The patient was operated upon the next day under novocaine infiltration anaesthesia. There was profuse bleeding at the time of removal, but it was easily controlled. The growth had not involved the sclerotic. The patient was discharged on January 4, 1926. Immediately after removal the thick layer of horny epithelium capping the top of the growth easily came off, exposing its rounded and nodular top. On squeezing it it felt tough, and no secretion, either pus or fluid could be obtained.

The characters of this disease are as follows :-It affects stratified epithelium, it forms cysts of varying sizes 3 to 4 microns in diameter containing 8 to 15 spores and lined by flat epithelium. The cyst bursts, discharging spores after they have grown. The cyst is then invaded by leucocytes.

The growth was kindly examined pathologically by the pathologist of the Grant Medical College, who pronounced it to be rhinosporidium Kinealyi.

The microscopic section contained a fair amount of fibrous and fibro-cellular tissue (granulation tissue rich in plasma cells) and typical cysts of rhinosporidium. The cysts were situated in the sub-epithelial layer and were irregular in size, shape and distribution according to the different stages of the growth. Some contained granular material, while others were quite empty. Four microphotographs of the growth are appended herewith.

In microphotograph No. 1 , with $\frac{2}{3}$ in. $\times 3$ Leitz, the proliferated stratified epithelium is seen prolonged into the subepithelial tissue where the cysts are situated. In No. 2, magnified $\times 400$, the small cyst is seen with its intact wall and spores. The larger one which is fully matured shows proliferation of epithelium lining it and invasion of leucoytes for absorption, but the third one above the second is seen in a burst condition. In No. 3 , with $\frac{1}{6}$ in. and 3 Leitz, a large single cyst is shown with proliferating epithelium and leucocytes invading it. In No. 4 with $\frac{1}{6}$ in. and 3 Leitz, an individual mature cyst is shown stained by Gram-Weigert stain. Within it the deeply stained spots are the spores, while the faintly stained ones are the blood cells.

Cultural. It grows on Sabouraud's medium and cultures were described by Lt.-Col. Iyer at the Indian Science Congress, 1927. Inoculations into rabbits, mice, guinea pigs or other laboratory animals, subconjunctival, subcutaneous, submucous and intraperitoneal, do not give any results.

Remarks. (1) It is strange that the growth should be found occurring in a Mohammedan, as was noticed by Elliot and Kirkpatrick. ${ }^{(6)}$ 


\section{Case of Rhinosporidium Kinealyi}

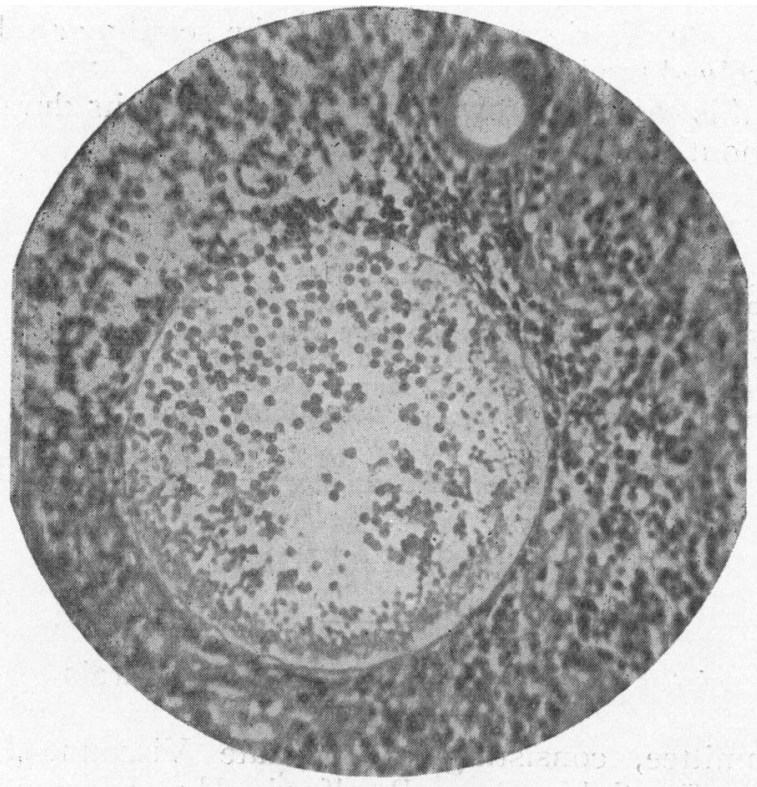

No. 3. $-\frac{1}{6}$ in. $\times 3$ Lettz.

A large single cyst with proliferated epithelium and leucocytes invading it.

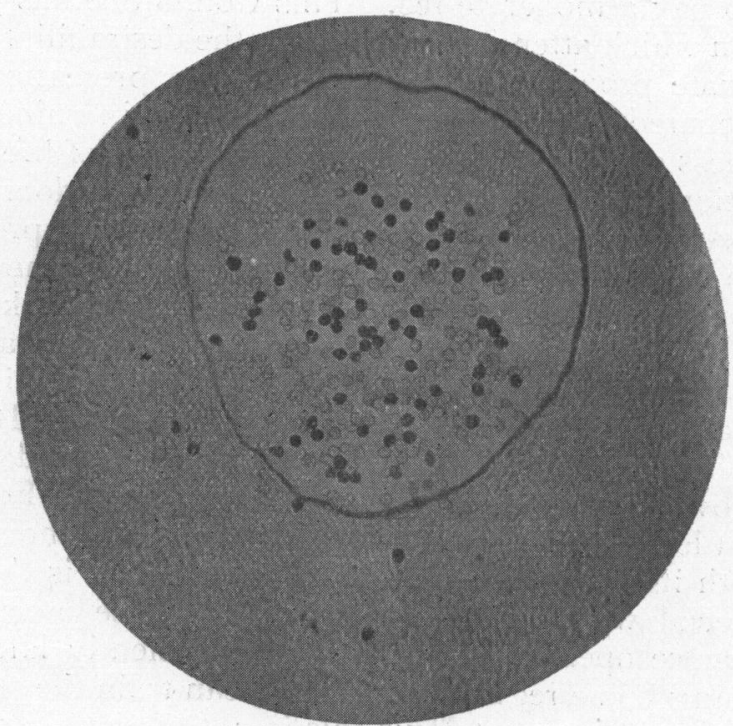

No. 4. $-\frac{1}{6}$ in. $\times 3$ Leitz. 
(2) The site of origin was possibly the semilunar fold, though later it involved the bulbar conjunctiva.

(3) In this case the growth was pretty rapid, its duration being only six months.

\section{REFERENCES}

1. Ball.-Modern Ophthalmology, p. 414.

2. Elliot and Ingram. - The Ophthalmoscope, August, 1912.

3. Kirkpatrick. - The Ophthalmoscope, September, 1916.

4. Tirumurti.-Practitioner, London, November, 1915.

5. Wright.-Indian Med. Gas., March, 1922.

6. Elliot.-Tropical Ophthal.. pp. 200 and 204.

\section{ANNOTATIONS}

\section{"Pay-beds" in Voluntary Hospitals}

A Committee, consisting of the late Viscount Hambleden (chairman), Sir John Rose Bradford, Mr. Warren Low and Professor Winifred Cullis, was appointed last year to investigate the question of the accommodation available in London for patients prepared to pay a moderate fee. This Committee has just issued its report, in which attention is drawn to the desirability of a much more adequate provision for the middle and professional classes who are prepared to pay sums of from four to six guineas a week. Serious illness or surgical operations in this class of life are a very grave addition to an annual expenditure that is seldom much less than the income. The report states that there are at present 1,055 pay-beds in the London hospitals, and suggests that new wings to existing hospitals or even separate hospitals might make good the deficiency. It is obvious to any hospital surgeon that it is not possible to make use of any of the present beds for this purpose ; these are none too many and waiting lists are long. It is further suggested that for the more wealthy patients accommodation might well be provided that could show a clear profit. For surgical purposes, at least, even the best nursing home falls short of a good hospital with its resident staff. More particularly is this the case in such special work as ophthalmology. Those more fortunate surgeons whose operative work is on a sufficiently large scale to keep a nursing home regularly supplied, can train the staff to their requirements, but for most of us this is not the case, and we have to be not only surgeon, but also nurse and house-surgeon.

The Times published a leading article on the subject on July 26 , in which it strongly supported the work of the British Provident 